\title{
Severe Generalized Spinal Cord Atrophy and Marfan Syndrome: A Case Report
}

\author{
Huanquan Liao*, Hongyan Zhou*, Ling Chen\# \\ Department of Neurology, First Affiliated Hospital, Sun Yat-sen University, Guangzhou, China \\ Email: "sumsdiy@163.com
}

Received 22 October 2015; accepted 6 November 2015; published 12 November 2015

Copyright (C) 2015 by authors and OALib.

This work is licensed under the Creative Commons Attribution International License (CC BY). http://creativecommons.org/licenses/by/4.0/

(c) $\underset{\mathrm{EY}}{\mathbf{B}}$ Open Access

\begin{abstract}
Generalized spinal cord atrophy is rare. Several causes can be found responsible for this entity. Marfan syndrome (MS) is a clinically and allelically heterogeneous, heritable connective tissue disorder. Previous study has implicated neuromuscular involvement in this syndrome. Here, we report the description of a patient with generalized spinal cord atrophy, which may be attributed to MS. Though not all patients represent with spinal cord atrophy, our case suggests that generalized spinal cord atrophy may occur in a subgroup of MS patients. Our finding underscores the need to inform medical practitioners that neurologic involvement, especially generalized spinal cord atrophy, can occur in patients with MS. Further studies are warranted in order to better clarify this causal relationship association between MS and spinal cord atrophy.
\end{abstract}

\section{Keywords}

Generalized Spinal Cord Atrophy, Marfan Syndrome

Subject Area: Neurology

\section{Introduction}

Generalized spinal cord atrophy is rare. Several causes can be found responsible for this entity [1] [2]. Marfan syndrome (MS) is a clinically and allelically heterogeneous, heritable connective tissue disorder caused by mutation in the gene encoding the extracellular matrix protein fibrillin-1 (FBN1), resulting in a defect in the production of fibrillin, and most often affecting the skeletal, respiratory, cardiovascular and ocular systems [3]. Previous study has implicated neurologic, especially neuromuscular involvement in this syndrome [4]. The following report is the description of an MS patient with generalized spinal cord atrophy, which may be most likely secondary to the weakened connective tissue of the spinal cord, or to the spinal cord ischemia caused by small

\footnotetext{
${ }^{*}$ These authors contributed equally.

${ }^{\#}$ Corresponding author.
} 
vessel dysfunction.

\section{Case Report}

The patient, a 21-year-old male from Guangxi province, who was a college student, was admitted on September 29, 2014, because of a quadriplegia which had proceeded over the previous 1 month. He suffered from pulsatile headache and fever (body temperature ranged from $38.0^{\circ} \mathrm{C}-39.0^{\circ} \mathrm{C}$ ) since August 08, 2014. Upon the onset of the symptoms, he was once treated as an out-patient in a local clinic with the diagnosis of upper respiratory infection. The therapy included oral amoxicillin and ribavirin. Nevertheless, the symptoms were not relieved, the body temperature increased to $39.0^{\circ} \mathrm{C}-41.0^{\circ} \mathrm{C}$ and there was sphincter dysfunction. After his hospitalization in a local countryside hospital on August 11 2014, his anti-infective therapy was upgraded including piperacillintazobactam and azithromycin, but the treatment effect was still not significant. On August 13, 2014, examination of cerebrospinal fluid (CSF) by lumbar puncture revealed a relatively high pressure of $170 \mathrm{~mm} \mathrm{H}_{2} \mathrm{O}$. The leucocytes concentration was $235 \times 10^{6} / \mathrm{L}$. Biochemical indicators revealed a relatively high protein concentration of $1536 \mathrm{mg} / \mathrm{L}$ and a relatively low glucose concentration of $2.2 \mathrm{mmol} / \mathrm{L}$ (serum concentration $6.2 \mathrm{mmol} / \mathrm{L}$ ). He was then treated with suspected diagnosis of 'central nervous system tuberculosis'. The therapy included rifampicin, isoniazid, pyrazinamide and ethambutol. However, the outcome seemed to be unrewarding and there was paralysis in the lower extremities. At the same time, he began vomiting after eating.

Consequently, on August 17, 2014, he was transferred to a provincial hospital, with suspected diagnosis of "central nervous system tuberculosis" or "acute disseminated encephalomyelitis". On August 18, 2014, the patient suffered dyspnea and unconsciousness. He was given trachea intubation and mechanical assisted ventilation. Gradually, paralysis began to appear in the upper extremities. He was not able to move on the bed at all. The patient was treated with large dose of methylprednisolone (anti-inflammatory), human gammaglobulin and mannitol, yet the improvement was still dissatisfied.

On September 29, 2014, the patient arrived at our hospital for further diagnosis and treatment. There was no family history of similar quadriplegia. However, he complained of blurred vision over the past 3 years. On examination, the patient exhibited the classic signs of MS [5]: tall stature (184 cm in height), long extremities, slender fingers, pectus excavatum, and arachnodactyly (Figure 1). On neurological examination, he was alert, cooperative and orientated. He had no speech disturbance. Cranial nerve examinations were normal. Flaccid quadriparesis was observed. Muscle tone was decreased. Tendon reflexes in all four extremities were weakened. Muscle strength in the upper and lower extremities was decreased (MRC grade 0 ). There was no clonus. In addition to quadriparesis, the patient had pin-prick, touch sensory and vibratory stimulation deficit within the four

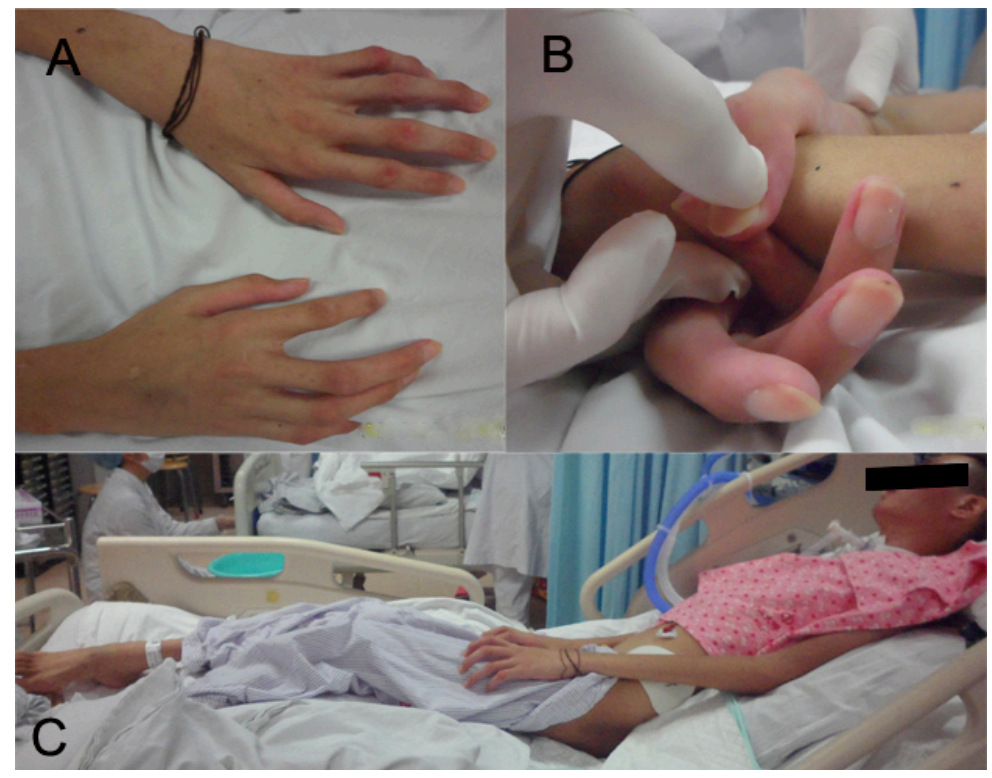

Figure 1. Classic signs of MS: arachnodactyly (A), slender limbs (B), tall stature (184 cm in height) and long extremities (C). 
extremities. There was neither atrophy nor fasciculation. There was no evidence of extrapyramidal dysfunction. After hospitalization, more detailed examination was undertaken. The parameters of routine blood test revealed elevated proportion of neutrophils $(82.8 \%)$, while the leukocyte count was normal. Blood clotting test, liver and kidney function test, blood glucose level, electrolytes level, routine urine and stool tests were normal. The tests for infectious diseases (hepatitis B, syphilis, and human immunodeficiency virus) were negative. Immune indexes (antinuclear antibody, anti-double stranded DNA antibody, anti-histone antibody, anti-nucleosome antibody, anti-DNP antibody, anti-SSA antibody, anti-SSB antibody, anti-SM antibody, anti-Jo1 antibody, anti-RNP antibody, anti-SCL70 antibody, and anticardiolipin antibody) were within the normal range. On September 29, 2014, the lumbar puncture and the CSF examination were carried out again. The CSF pressure was $270 \mathrm{~mm}_{2} \mathrm{O}$, leucocytes level was $19 \times 10^{6} / \mathrm{L}$, and protein level was $1010 \mathrm{mg} / \mathrm{L}$. Other biochemical indicators were normal. Pandy's test, tests for Gram-negative bacilli, Gram-negative cocci, acid-fast bacilli, and Staphylococcus aureus, and T-spot were negative. The immunoglobulin-G index was within normal limits and anti-aquaporin 4 antibodies were not detected. Cryptococcus or mycobacterium tuberculosis was not found. There was no heterocyst. Magnetic resonance imaging (MRI) revealed severe generalized spinal cord atrophy along with abnormal signals in the bilateral brain white matter surrounding the ventricle, the mesocephalon, the medulla oblongata and the cervical spinal cord (Figure 2). Electromyography disclosed denervation potentials accompanied by mild reductions in the motor and sense nerve conduction in the bilateral median nerve, axillary nerve, ulnar nerve, femoral nerve, tibial nerve and peroneal nerve, respectively. F-waves assessment was also abnormal. Two-dimensional, M-mode, and color echocardiography revealed aortic abnormality. The ascending aortic dimension was also slightly dilatated $(34 \mathrm{~mm})$. His left ventricular function was normal with a left ventricular ejection fraction of $79 \%$. The left ventricular cavity was normal with a left ventricular end-diastolic dimension of $50.2 \mathrm{~mm}$. However, slit lamp did not reveal ectopia lentis.

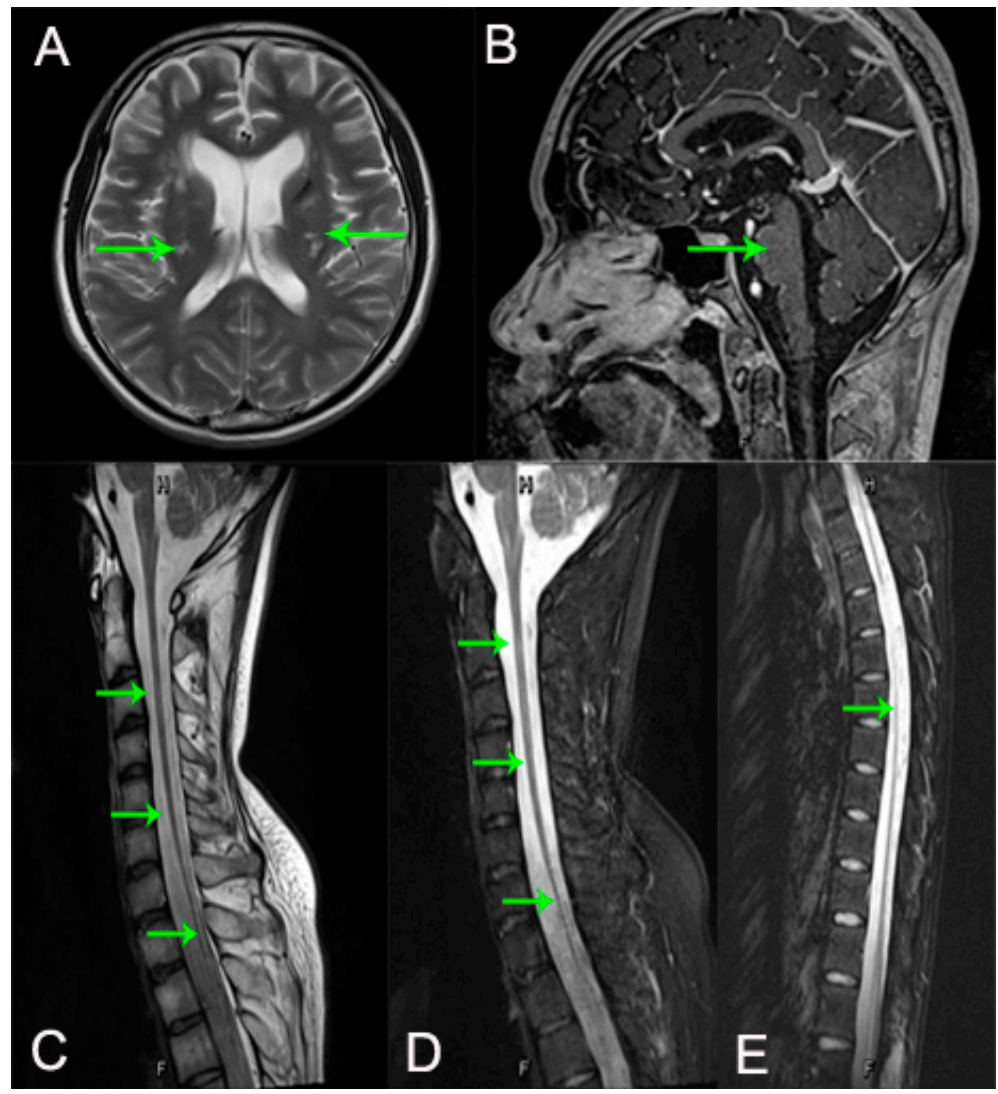

Figure 2. MRI revealed severe generalized spinal cord atrophy (arrows, C, D and $\mathrm{E}$ ) along with abnormal signals in the bilateral brain white matter surrounding the ventricle (arrows, A), the mesocephalon, the medulla oblongata and the cervical spinal cord (arrow, B). 
The treatment regiment described above was continued in the following 6 months. His muscle strength in the four extremities gradually improved to about MRC grade 2. He was able to get rid of mechanical assisted ventilation. Several times of lumbar puncture and CSF examination were done. Biochemical indicators were normal. However, the CSF pressure was still relatively high, at about $200 \mathrm{~mm} \mathrm{H}_{2} \mathrm{O}$.

\section{Discussion}

The dominant feature in the presented patient was severe spinal cord atrophy. Generally, spinal cord atrophy may be focal or generalized. Focal spinal cord atrophy may be due to Chiari malformation, previous central nervous system (CNS) infection, trauma, radiotherapy, spinal surgery, immunological disorder, vascular abnormality or CNS tumour [1] [2] [6]-[9]. Generalized spinal cord atrophy is rare and may be due to Chiari malformation, luetic CNS infection [10], and hereditary disorders like arthrogryposis multiplex congenita [11], Chediak-Higashi syndrome [12], adrenoleucodystrophy [13], familial spastic paraparesis [14], and hereditary motor and sensory neuropathy with pyramidal signs [7]. Apart from these causes, our reported patient suggests that generalized spinal cord atrophy may also be attributed to MS.

MS is a heritable connective tissue disorder characterized by a varying pattern of organ involvement including the cardiovascular, eyes, skeleton, skin, and dura. Many symptoms do not appear until puberty or later, and severe complications rarely develop before adulthood. With increasing life expectancy, the life-threatening cardiovascular involvement shifts to more chronic ocular, orthopedic, and, possibly, neurologic complications [15][19].

In Voermans' comprehensive investigations, myopathy, polyneuropathy and lumbosacral radiculopathy involvement were revealed in the majority of MS patients. Our findings underscore the need to inform medical practitioners that the range of complications that can occur in patients with MS extends from cardiovascular, ocular, and orthopedic symptoms to neurologic involvement. Generalized spinal cord atrophy in MS is probably due to our increasing insight into the role of extracellular matrix molecules in neurologic pathophysiology [20]. EMG result indicated that our patient had an axonal polyneuropathy. Although fibrillin-1 and fibrillin-2 have been found in the connective tissue sheaths of peripheral nerves [21], peripheral neuropathy in MS has only been reported once [22]. Abnormal packing of peripheral nerves due to fibrillin deficiency may increase the susceptibility to pressure or stretch, as in other heritable connective tissue disorders [23]. Our patient suggested that fibrillin abnormalities also affect axonal functioning. A further comparison can be made with Ullrich congenital muscular dystrophy and Bethlem myopathy, both of which are caused by collagen VI deficiency [24]. These findings are important to report because of the paucity of literature regarding central nervous system abnormalities especially the spinal cord in MS. The true incidence of spinal cord abnormalities in MS is not known because neuroimaging and/or neuropathology have rarely been reported in this group of patients. To the best of our knowledge the neuroradiologic findings reported by us have not been previously reported. It is not known whether the generalized spinal cord atrophy in our case contributed to the patient's neurologic abnormalities. As fibrillin-1 is found in all arterial wall layers, it is thought to play an important role in maintaining the structural integrity of the vascular system [25]. We speculate that the generalized spinal cord atrophy in our case is the result of spinal cord ischemia caused by small vessel dysfunction.

However there was no dural ectasia in our patient, while radiculopathy caused by lumbosacral dural ectasia with spinal meningeal cysts may contribute to weakness and atrophy in MS [26]. Dural ectasia is probably caused by a weakening of the connective tissue of the dural sac due to fibrillin-1 deficiency [26].

\section{Conclusion}

In short, our reported MS patient examined in this study showed neurologic involvement, primarily consisting of generalized spinal cord atrophy, myopathy and polyneuropathy, with some signs of (poly) radiculopathy. Although the clear association with generalized spinal cord atrophy has not yet been established, the result calls for further research in large groups, and, if confirmed, increased attention should be paid to neurologic symptoms, especially spinal cord atrophy.

\section{Conflict of Interest}

This is a case report without any industry-sponsorship. All of the authors report none to disclosure. 


\section{References}

[1] Pietrini, V., Pinna, V. and Milone, F.F. (1990) Tangier Disease: Central Nervous System Impairment in a Case of Syringomyelia-Like Syndrome. Journal of the Neurological Sciences, 98, 245-250. http://dx.doi.org/10.1016/0022-510X(90)90265-O

[2] Hirabuki, N., Mitomo, M., Miura, T., Hashimoto, T., Kawai, R. and Kozuka, T. (1991) Computed Tomographic Myelography Characteristics of Spinal Cord Atrophy in Juvenile Muscular Atrophy of the Upper Extremity. European Journal of Radiology, 13, 215-219. http://dx.doi.org/10.1016/0720-048X(91)90033-R

[3] Groenink, M. and Mulder, B.J. (2015) How to Treat Marfan Syndrome: An Update. European Heart Journal, Published Online. http://dx.doi.org/10.1093/eurheartj/ehv589

[4] Voermans, N., Timmermans, J., van Alfen, N., Pillen, S., Op, D.A.J., Lammens, M., et al. (2009) Neuromuscular Features in Marfan Syndrome. Clinical Genetics, 76, 25-37. http://dx.doi.org/10.1111/j.1399-0004.2009.01197.x

[5] Pyeritz, R.E. and Mckusick, V.A. (1979) The Marfan Syndrome: Diagnosis and Management. The New England Journal of Medicine, 300, 772-777. http://dx.doi.org/10.1056/NEJM197904053001406

[6] Riva, A. and Bradac, G.B. (1995) Primary Cerebellar and Spino-Cerebellar Ataxia an MRI Study on 63 Cases. Journal of Neuroradiology, 22, 71-76.

[7] Ueyama, H., Kumamoto, T., Asahara, K., Watanabe, S., Ando, Y., Mita, S., et al. (1993) Hereditary Motor and Sensory Neuropathy Type V with Spinal Cord Atrophy On Magnetic Resonance Imaging. European Neurology, 33, 399 400. http://dx.doi.org/10.1159/000116981

[8] Szalay, E.A., Roach, J.W., Smith, H., Maravilla, K. and Partain, C.L. (1987) Magnetic Resonance Imaging of the Spinal Cord in Spinal Dysraphisms. Journal of Pediatric Orthopaedics, 7, $541-545$. http://dx.doi.org/10.1097/01241398-198709000-00008

[9] Yamada, T., Tashiro, K., Moriwaka, F., Fujiki, N., Ito, K., Honma, S., et al. (1989) Two Cases of Familial Spastic Paraparesis with Amyotrophy of the Hands. No To Shinkei, 41, 583-588.

[10] El, A.M., Medejel, A., Al, Z.K., Yahyaoui, M. and Chkili, T. (1990) Amyotrophic Lateral Sclerosis Syndrome of Syphilitic Origin. 5 Cases. Revue Neurologique (Paris), 146, 41-44.

[11] Fedrizzi, E., Botteon, G., Inverno, M., Ciceri, E., D’Incerti, L. and Dworzak, F. (1993) Neurogenic Arthrogryposis Multiplex Congenita: Clinical and MRI Findings. Pediatric Neurology, 9, 343-348. http://dx.doi.org/10.1016/0887-8994(93)90102-I

[12] Uyama, E., Hirano, T., Ito, K., Nakashima, H., Sugimoto, M., Naito, M., et al. (1994) Adult Chediak-Higashi Syndrome Presenting as Parkinsonism and Dementia. Acta Neurologica Scandinavica, 89, 175-183. http://dx.doi.org/10.1111/j.1600-0404.1994.tb01657.x

[13] Snyder, R.D., King, J.N., Keck, G.M. and Orrison, W.W. (1991) MR Imaging of the Spinal Cord in 23 Subjects with ALD-AMN Complex. American Journal of Neuroradiology, 12, 1095-1098.

[14] Seichi, A., Hoshino, Y., Ikegawa, S., Tanaka, T., Yanagisako, Y., Kimitsuka, M., et al. (1993) Cervical Spinal Cord Atrophy Associated with Spina Bifida. Paraplegia, 31, 262-264. http://dx.doi.org/10.1038/sc.1993.46

[15] von Kodolitsch, Y. and Robinson, P.N. (2007) Marfan Syndrome: An Update of Genetics, Medical and Surgical Management. Heart, 93, 755-760. http://dx.doi.org/10.1136/hrt.2006.098798

[16] Dean, J.C. (2007) Marfan Syndrome: Clinical Diagnosis and Management. European Journal of Human Genetics, 15, 724-733. http://dx.doi.org/10.1038/sj.ejhg.5201851

[17] Jones, K.B., Sponseller, P.D., Erkula, G., Sakai, L., Ramirez, F., Dietz, H.R., et al. (2007) Symposium on the Musculoskeletal Aspects of Marfan Syndrome: Meeting Report and State of the Science. Journal of Orthopaedic Research, 25, 413-422. http://dx.doi.org/10.1002/jor.20314

[18] Ramirez, F. and Dietz, H.C. (2007) Marfan Syndrome: From Molecular Pathogenesis to Clinical Treatment. Current Opinion in Genetics \& Development, 17, 252-258. http://dx.doi.org/10.1016/j.gde.2007.04.006

[19] Hasan, A., Poloniecki, J. and Child, A. (2007) Ageing in Marfan Syndrome. International Journal of Clinical Practice, 61, 1308-1320. http://dx.doi.org/10.1111/j.1742-1241.2007.01407.x

[20] Lampe, A.K. and Bushby, K.M. (2005) Collagen VI Related Muscle Disorders. Journal of Medical Genetics, 42, 673685. http://dx.doi.org/10.1136/jmg.2002.002311

[21] Isogai, Z., Ono, R.N., Ushiro, S., Keene, D.R., Chen, Y., Mazzieri, R., et al. (2003) Latent Transforming Growth Factor Beta-Binding Protein 1 Interacts with Fibrillin and Is a Microfibril-Associated Protein. The Journal of Biological Chemistry, 278, 2750-2757. http://dx.doi.org/10.1074/jbc.M209256200

[22] Barrison, I.G., Isenberg, D.A. and Kane, S.P. (1980) Arachnodactyly with Unusual Neuromyopathic and Skeletal Abnormalities. Journal of the Royal Society of Medicine, 73, 64-68. 
[23] Voermans, N.C., Drost, G., van Kampen, A., Gabreels-Festen, A.A., Lammens, M., Hamel, B.C., et al. (2006) Recurrent Neuropathy Associated with Ehlers-Danlos Syndrome. Journal of Neurology, 253, 670-671. http://dx.doi.org/10.1007/s00415-005-0056-0

[24] Camacho, V.O., Bertini, E., Zhang, R.Z., Petrini, S., Minosse, C., Sabatelli, P., et al. (2001) Ullrich Scleroatonic Muscular Dystrophy Is Caused by Recessive Mutations in Collagen Type VI. Proceedings of the National Academy of Sciences of the United States of America, 98, 7516-7521. http://dx.doi.org/10.1073/pnas.121027598

[25] Dietz, H.C. and Pyeritz, R.E. (1995) Mutations in the Human Gene for Fibrillin-1 (FBN1) in the Marfan Syndrome and Related Disorders. Human Molecular Genetics, 4, 1799-1809.

[26] Fattori, R., Nienaber, C.A., Descovich, B., Ambrosetto, P., Reggiani, L.B., Pepe, G., et al. (1999) Importance of Dural Ectasia in Phenotypic Assessment of Marfan's Syndrome. The Lancet, 354, 910-913.

http://dx.doi.org/10.1016/S0140-6736(98)12448-0 